\title{
DIE VERHOUDING TUSSEN INDIKATIEF EN PARAKLESE IN DIE NUWE TESTAMENT, TOEGELIG VANUIT DIE EERSTE BRIEF AAN DIE TESSALONISENSE 1
}

\author{
L. Floor \\ Departement Nuwe Testament \\ Potchefstroomse Universiteit vir Christelike Hoër Onderwys \\ POTCHEFSTROOM
}

\begin{abstract}
The teaching on eschatology is of utmost importance in the first epistle of Paul to the Thessalonians. Regarding the parousia of Christ, Paul presents a number of instructions concerning the process of sanctification. When the apostle dcals with paranctic material, he does not command but request. Those who have been called to sanclification, should not continue to live in impurity, for God has given the Holy Spirit who is the Spirit of sanctification. The indicative of the parousia is linked with the paraclesis of sanctification by the Holy Spirit. God who called the members of the church in sanctification has given the Holy Spirit to fulfil all His obligations. In this anicle it is indicated that the relotion between indicative and paraclesis in this Epistle is of a pneumatological nature.
\end{abstract}

\section{DIE STAND VAN DIE NAVORSING}

Wie die jongste literatuur met betrekking tot Paulus se eerste brief aan die Tessalonisense raadpleeg, kom tot die ontdekking dat daar verskillende tendense na vore kom. In die eerste plek is daar navorsers wat in hulle studie baie groot erns maak met oorwegings vanuit die sosio-kulturele omstandighede van die skrywer en sy eerste lesers. Ons kan hier verwys na die werk van Malherbe (1987).

Hierdie benadering is vir ons nie heeltemal nuut nie, omdat daar in Kanoniek ook altyd aandag gegee is aan die outeur en sy eerste lesers en hulle lewensomstandighede, maar in die jongste navorsingsresultate kry die sosio-kulturele omstandighede die

\footnotetext{
${ }^{1}$ Hierdie artikel is 'n verwerking van 'n referaat wat gedurende Julie 1989 tydens 'n Winterskool van die Fakulteit Teologie van die PU vir CHO onder leiding van prof. J.C. Coetzee aangebied is. Die artikel veronderstel dus dat die leser ook die artikel van C.J.H. Venter wat as inleidende referaat tydens die kursus gedien het, gelees het. (In die Skriflig 24(1)1990:1-27.)
} 
gewig van 'n hermeneutiese sleutel. Aan die hand van nuwe sosiologiese ontwikkelinge word met 'n duidelik uitgewerkte metode na die Nuwe-Testamentiese teks gegaan. Die tweede tendens op die terrein van die navorsing is om by die eksegese van die Nuwe Testament gebruik te maak van antieke en ook moderne retoriese modelle. Met betrekking tot Paulus se eerste brief aan die Tessalonisense kan hier verwys word na die werk van Jewett (1986).

Dit is nie die bedoeling om met hierdie nuwere tendense op die terrein van die navorsing in 1 Tessalonisense in debat te tree nie, maar om 'n eie bydrae te lewer tot die verstaan van hierdie brief en dan besonderlik om 'n insig te kry in die verhouding van die indikatief tot die paraklese.

\section{DIE STRUKTUUR VAN DIE BRIEF}

Paulus se eerste brief aan die Tessalonisense, waarskynlik een van sy oudste briewe, vertoon 'n opvallende struktuur. Al word in hierdie brief 'n veelheid van onderwerpe behandel, is daar tog een bepaalde tema wat telkens in die brief terugkeer en dominant na vore kom: die tema van die wederkoms van Christus. Hierdie tema het 'n alles verbindende funksie. Verskillende onderwerpe word dan ook aan die groot tema van die wederkoms gekoppel. Versteeg (1987:420) kom in verband met hierdie alles beheersende tema tot die volgende indeling van die eerste brief aan die Tessalonisense:

- bekering en wederkoms

- apostoliese diens en wederkoms

- heilige lewenswandel en wederkoms

- die ontslapenes en wederkoms

- waaksaamheid en wederkoms
3:1-4:12

$4: 13-18$

$5: 1-28$

Twee leerstellige sake word deur Paulus in hierdie brief prominent na vore gebring: sedelike heiligheid, en in verband daarmee, die wederkoms van Christus. Ook elders in die Nuwe Testament word daar 'n noue samehang geteken tusssen wederkoms en heiligmaking (vgl. 1 Joh. 3:3). Coetzee (1980:34,35) sien ook die wederkoms van Christus en in verband daarmee sedelike heiligmaking as die kernmotiewe van hierdie brief.

Dit lyk of die apostel ten opsigte van die twee leerstellinge wat hy behandel, gebruik maak van 'n spiraalstruktuur soos De Klerk (1983) in sy proefskrif oor die gesag van 
die prediking van die Nuwe-Testamentiese briewe oortuigend aangetoon het. Heiligmaking kom in $1: 9,2: 12$ en $3: 13$ ter sprake en word dan breedvoerig bespreek in $4: 1$ 12.

So ook word die wederkoms breedvoerig bespreek. In 1:10, 2:16 en 3:13 duik die wederkoms-motief op en aan die slot van die brief, in 4:13-5:12, word breedvoerig oor die wederkoms gehandel (De Klerk, 1983:338).

\section{DIE KOPPELING VAN INDIKATIEF EN PARAKLESE}

Hoewel daar in Paulus se eerste brief aan die Tessalonisense ' $n$ veelheid van onderwerpe ter sprake kom, is die wederkoms-motief sonder enige twyfel die grootste heilsindikatief wat in hierdie brief aan die orde gestel word. Aan hierdie heilsindikatief is onlosmaaklik die imperatief van 'n heilige lewe van die gelowige gekoppel.

Die koppeling tussen indikatief en paraklese kom duidelik na vore in die wentelpunt waar die skrywer baie pertinent die imperatief ter sprake bring. Van Leeuwen (1926:91), Best (1977:154), Morris (1976:72), Versteeg (1987:419) is van oordeel dat ons in 1 Tessalonisense 4:1,2 'n duidelike oorgang van die indikatief na die paraklese kry.

In 1 Tessalonisense 4:1,2 lees ons die oproep om te leef soos God dit wil. Die oproep lui: "Lê julle nog meer daarop toe om te lewe soos God wil hê julle moet lewe".

Die motivering vir die oproep is: "... julle ken die voorskrifte wat ons op gesag van die Here Jesus aan julle oorgedra het".

Dit lyk of Paulus hier van 'n vaste formule gebruik maak. Bjerkelund (1967:125-140) het ' $n$ ondersoek ingestel na wat hy noem paranetiese materiaal (paraenetic material) by Paulus, en hy het tot die konklusie gekom dat die apostel sowel in Romeine 12:1; $15: 30 ; 16: 17$; 1 Korintiërs $1: 10 ; 4: 16 ; 16: 15 ; 2$ Korintiërs $10: 1$; asook in 1 Tessalonisense 4:1,2 gebruik maak van 'n vaste paranetiese formule. Hierdie formule bestaan uit vier kernpunte: 
- die werkwoord in die eerste persoon,

- die adres (broeders)

- 'n preposisionele frase

- 'n versoek wat df met 'n hina-sin begin df met 'n infinitief.

Soos so dikwels in sy briewe begin Paulus sy paraklese met die partikel: oûv, daarom, derhalwe. Ridderbos (1959:273) beskou 'oûn' "slechts als een overgangspartikel", maar dit lyk tog of hierdie klein partikel groot betekenis het. Lloyd-Jones (1980:11-22) het in sy bespreking van hierdie partikel in Efesiërs 4:1 selfs 'n hele hoofstuk aan daardie klein woordjie gewy.

Ook in ander briewe van Paulus soos sy brief aan die Romeine (12:1) en sy brief aan die Efesiërs, kry ons 'n soortgelyke oorgang van die leerstellige deel na die parakletiese deel.

Dit is wel duidelik dat die apostel met behulp van hierdie partikel 'n verbinding lê

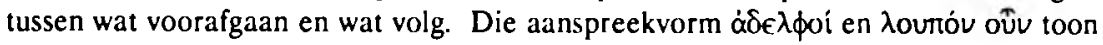
aan dat Paulus hier met 'n nuwe deel, of soos genoem word 'n parakletiese deel begin (De Klerk, 1983:368). Die oorgangspartikel het dus 'n brugfunksie. Op hierdie wyse word die oorgang van die indikatief na die paraklese, van die dogmatiek na die etiek, van die leer na die lewe gemaak.

Dit beteken egter nie dat in hierdie brief, soos ook elders in die Corpus Paulinum, die indikatief waterdig van die paraklese geskei is nie. Hoewel daar sprake is van 'n sekere afbakening van die paraklese teenoor die indikatief, is daar by Paulus ook'n vervlegting van die indikatief en die paraklese. In die meer leerstellige deel van sy brief vind ons reeds verskillende parakletiese gegewens en in die meer parakletiese deel word weer duidelik allerlei leerstellige onderwerpe behandel.

Nou is dit besonder opmerklik dat Paulus, alvorens hy in 4:1 die groot oorgang van die indikatief na die paraklese mak en die paraklese dan ook veral op 'n bepaalde lewensterrein gaan tocspits, die paraklese van lewensheiliging en geestelike groei op 'n merkwaardige wyse aan die slot van hoofstuk 3 ter sprake bring. Paulus skrywe in 3:13: "Hy sal julle innerlik sterk maak dat julle onberispelik en heilig voor God ons Vader sal staan wanneer ons Here Jesus kom saam met al sy heilige engele".

In 3:2 skrywe Paulus reeds oor die innerlike versterking. Daar is dit 'n taak wat aan Timoteus toevertrou is. Hier in 3:13 word die innerlike versterking gesien as 'n werk 
van God. Innerlike versterking, geloofsgroei, heiligmaking is dus primêr die werk van God. Hoewel heiligmaking die inhoud van die paraklese is, moet ons goed daarop let dat heiligmaking tegelyk ook inhoud van die indikatief is. By Paulus is heiliging selfs in die eerste plek 'n gawe en daarna ook 'n opgawe. In 1 Tessalonisense 4:7 skrywe Paulus dat heiligmaking 'n roeping is vir elke gelowige. Ons is geroep om heilig te lewe. Hier het ons dus 'n duidelike paraklese. Velema (1985:37) skryf tereg by hierdie teks: "Men denke niet dat Paulus nu op een ander spoor overgaat, als zou de heiliging nu ineens inhoud van het bevel en niet langer inhoud van de gave zijn". Die indikatief van die heiliging en die paraklese van die heiliging is in die apostoliese prediking dus op ' $n$ besondere manier met mekaar verweef. Ons sien in 1 Tessalonisense 4:1 dat deur middel van die partikel die indikatief van die heiliging (3:13) met die paraklese van die heiliging (4:2) verbind word. Om die regte verhouding tussen indikatief en paraklese in Paulus se eerste brief aan die Tessalonisense raak te sien, sal ons veral moet kyk na 'n bepaalde perikoop, naamlik 1 Tessalonisense 4:1-8. 'n Visuele voorstelling van die gedagtegang lyk soos volg:

4:1+2: Oproep om te leef soos God dit wil

4:1: $\quad$ Die oproep

4:2: $\quad$ Motivering vir die opproep

4:3+7: God roep ons op tot heiligmaking

4:3a: 'n Algemene stelling: God wil dat ons heilig lewe

4:3b: Weerhou julle van onsedelikheid

4:5,5: Ontheilig nie die huwelik nie

4:6: $\quad$ Maak nie inbreuk op die huwelik van 'n ander nie

\section{4:9: $\quad$ Gevolgtrekking}

Jewett (1986:73) kom in sy retoriese analise van 1 Tessalonisense $4: 1-8$ tot 'n soortgelyke struktuurontleding.

\section{DIE HEILSKARAKTER VAN DIE PARAKLESE}

Wanneer Paulus die Tessalonisense in 1 Tessalonisense 4:1 oproep tot 'n heilige lewe,

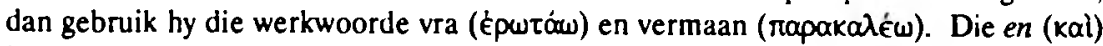
is hier epeksegeties. Paulus kom met 'n vraag tot die gelowiges in Tessalonika, maar dan 'n vraag in die vorm van 'n versoek of ' $n$ vermaning. Die vraagformule wat Paulus 
gebruik, is in daardie tyd dikwels deur Joodse skrywers met 'n Hellenistiese agtergrond gebruik.

Paulus gebruik hier twee werkwoorde, naamlik vra en vermaan. Deur twee werkwoorde in plaas van een te gebruik, beklemtoon die apostel die belangrikheid van wat gesê

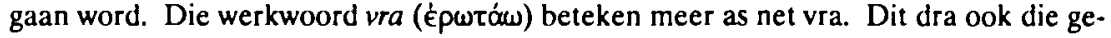
voel van smeek en selfs bid (vgl. 5:12).

Die tweede werkwoord rapakkaléw in Paulus se vraagformule is deur skrywers in daardie tyd gebruik wanneer hulle gekommunikeer het met persone van dieselfde status (Best, 1977:155). Dit het nie die konnotasie van vermaan soos De Klerk dit stel nie (1983:368), maar van versoek (Bjerkelund, 1967:188).

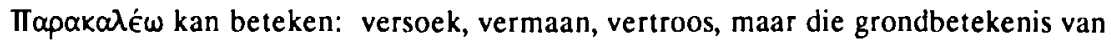
hierdie werkwoord is herbeiführen (Schmitz, 1954:777).

Letterlik sou ons hierdie teks soos volg moet vertaal: ek vra en roep julle by wat julle van ons geleer het (Louw \& Nida, 1988:423-424). Dit bring ons by die heilskarakter van die paraklese. Paulus sê nie vir die gemeente te Tessalonika dat hy hulle gebied nie. Dit doen die owerheid. Hy gebied en beveel deur sy wette en verordeninge. Ook word nie deur Paulus gesê dat hy hulle dwing nie. Dit doen die polisiemag, die sterk arm van die owerheid. Ook sê Paulus nie vir sy lesers dat hy hulle adviseer nie. So maak 'n verkoopsman. Nee, Paulus skrywe vir sy lesers: "Ek roep julle tot by die dinge wat julle van ons geleer het". Die indikatief van die verkondiging sal die gelowiges aanvuur om die paraklese van die heiliging van die lewe te gehoorsaam.

Die indikatief is die voedingsbodem vir die paraklese. Sowel indikatief as paraklese maak ' $n$ appèl op die reseptiewe aard van die geloof en die paraklese op die aktiewe aard van die geloof. In die betrokkenheid van sowel die indikatief as die paraklese op die geloof is die eenheid van indikatief en paraklese veranker.

Die noue verbondenheid van indikatief en paraklese bring aan die lig dat ons die heilskarakter van die paraklese moet raaksien. Dit is nie so dat die indikatief betrekking het op God en op sy heil in Christus Jesus en dat die paraklese net betrekking het op die mens nie. Sowel indikatief as paraklese is betrokke op God se heil in Christus Jesus. Soos ons praat van heilsindikatief, so sou ons ook kon praat van 'n heilsparaklese. 


\section{DIE INHOUD VAN DIE HEILSPARAKLESE}

Die dinge wat Paulus die gelowiges in Tessalonika geleer het $(4: 1)$, noem hy

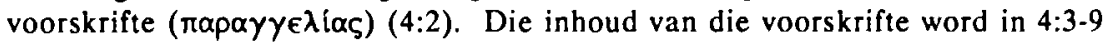
uiteengesit.

In 4:3 vat Paulus die inhoud van die voorskrifte kort en kragtig saam met die uitdrukking julle heiligmaking. God wil dat hulle heilig lewe. Paulus spits dan die heiligmaking veral toe op die huwelik.

Die verse 3 tot 7 vorm 'n ringkomposisie. Volgens De Klerk (1983:367) maak die apostel van die ringkomposisie gebruik om die krag van sy konkrete bevele insake die sedelike lewe aan die leser weer te gee.

Wanneer ons die gedagtegang van die apostel in 1 Tessalonisense 4:3-7 volg, dan sien ons dat Paulus eers 'n algemene stelling maak:

vs. 3a: Dit is die wil van God dat julle heilig moet lewe.

Vervolgens word die algemene stelling in verse $3 b-6$ toegespits op die volgende:

vs. 3b: Weerhou julle van onsedelikheid

vs. 4-5: Ontheilig nie die huwelik nie

vs. 6: $\quad$ Maak nie inbreuk op die huwelik van 'n ander nie.

In vers 7 word die algemene stelling herhaal, en dan gee Paulus in vers 9 ' $n$ afsluitende gevolgtrekking.

Die begrip heiligmaking ( $\alpha$ y $\left\llcorner\sigma \mu \sigma_{\varsigma}\right.$ ) omkring hierdie semantiese eenheid. In hierdie konteks is die teenoorgestelde betekenis van $\dot{\alpha} \gamma\left\llcorner\alpha \sigma \mu o_{\zeta}\right.$ hoerery (ropveía). Heiligmaking hou drie dinge in:

- om hoerery te ontvlug (4:3),

- om elkeen sy eie vrou in heiligheid en eerbaarheid te verkry (4:4),

- om niemand in hierdie saak te benadeel nie (416).

Onsedelikheid was een van die sondes wat in die heidenwêreld algemeen aanvaar is. Daarom neem Paulus so 'n sterk standpunt teenoor hoerery in. Heiligmaking het hier 
die betekenis van sedelike reinheid, en die klem is dan nie op die verhouding tot God nie. Hoewel die klem hier nie val op ' $\mathrm{n}$ verhouding tot God nie, is dit wel aanvullend hierby betrokke. Die sedelike reinheid spruit voort uit die verhouding tot God, naamlik om Hom te behaag, soos Paulus in 4:1 geskryf het (S.J. Floor, 1983:46,47). Dit is moeilik om presies vas te stel wat Paulus in 4:6 bedoel waar hy skrywe dat niemand sy broeder in hierdie saak moet bedrieg of benadeel nie, of soos De Klerk vertaal: nie inbreuk maak op die huwelik van 'n ander nie (1983:369).

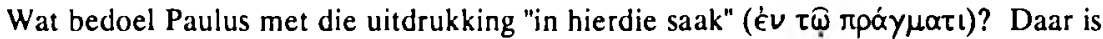
eksegete (Calvyn, 1875:161,162; Wohlenberg, 1909:92,93; Van Leeuwen, 1926:356; Staab, 1950:26; Schrage, 1961:62; Rossano, 1954:257; Beauvery, 1955:78), wat meen dat Paulus hier van die huwelik oorstap na die sakelewe. Omdat Tessalonika 'n handelstad was, het die gemeente te Tessalonika hoofsaaklik bestaan uit mense wat handel gedryf het. Bedrog, uitbuiting en oneerlike handelspraktyke was aan die orde van die dag in dié heidense leefwêreld. Daar is ook Skrifverklaarders wat oordeel dat Paulus met die uitdrukking "in hierdie saak" die regspraak op die oog het en dat hy wil waarsku teen onregverdige eise in 'n hofsaak (Dibelius, 1937:22; Delling, 1959:271).

Daar is egter ook 'n groot aantal eksegete wat oordeel dat Paulus met die uitdrukking "in hierdie saak" eenvoudig verwys na wat hy reeds in 4:3,4,5 aan die orde gestel het, naamlik hoerery en 'n eerbare huwelikslewe. Dan bly die apostel gewoon by sy onderwerp (vgl. Schatter, 1921:98; Frame, 1912:154; Mason, 1957:48,49; Rigaux, 1956:510; Bolkestein, 1974:101).

\section{DIE ROL VAN DIE HEILIGE GEES IN DIE VERHIOUDING INDIKATIEF- PARAKLESE}

Wanneer Paulus die paraklese van heiligmaking so sterk beklemtoon, wys hy ook op die rol wat die Heilige Gees in die verhouding indikatief-paraklese speel. Hy doen dit in 1 Tessalonisense 4:8. In hierdie vers sluit die apostel dié deel van sy betoog met'n gevolgtrekking af:

Wie hierdic voorskrifte verwerp, verwerp dus nic maar net 'n mens nic, hy verwerp God wat ook sy Heilige Gees aan julle gegee het."

Paulus begin sy betoog met 'n driedubbele sterk partikel tolyapouv. Dan gryp hy weer terug na vers 2 en spreek weer oor die voorskrifte wat op gesag van Jesus Christus aan 
die gelowiges te Tessalonika oorgelewer is. Die inhoud van daardie voorskrifte is die oproep tot 'n heilige lewenswandel. Paulus bring dan die voorskrifte nie soos in vers 2 in verband met die Here Jesus nie, maar met God. God eis gehoorsaamheid aan die voorskrifte wat gegee is.

In 4:2 het Paulus reeds duidelik aangetoon dat hy met die bevel van 'n offisier gekom het en dat sy bevele as menslike gesant die gesagstempel van sy Sender, die Here Jesus, dra. Hier in vers 8 druk hy hom nog sterker uit. Die bevele wat hy verkondig het, kan verwerp word. Deur die participium praesens te gebruik ( $\dot{\alpha} \theta \epsilon \tau \hat{\omega} \nu$ ) skets die apostel iemand wat aktief en openlik en voortdurend die bevele verwerp, opsyskuif en verkleineer. lemand wat dit aktief en openlik doen, verwerp nie 'n mens of menslike voorskrifte nie, ook nie alleen 'n goddelike bevel nie, maar hy verwerp God self (De Klerk, 1983:373). Best (1977:169) vermoed dat Paulus hier met die uitdrukking "verwerp nie 'n mens nie maar God", die Joodse beginsel van die shaliach in gedagte gehad het.

Vervolgens kom die apostel in 1 Tessalonisense 4:9 met 'n besonder belangrike openbaring aangaande God. Hy skryf aan die Tessalonisense dat God nie alleen maar 'n God is wat eis, wat vra nie; $\mathrm{Hy}$ is in die eerste plek 'n God wat gee.

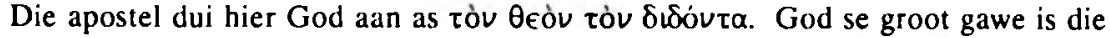
Heilige Gees. Paulus druk hom op 'n merkwaardige manier uit. Hy skrywe: "God het aan julle die Gees van Hom die Heilige gegee". Die woord Heilige (äyıov) kry op hierdie manier 'n besonder sterk beklemtoning. Hierdeur word ook tot uitdrukking gebring dat dit die Gees van God is wat die heiligmaking bewerk (Van Leeuwen, 1926:359).

God is die Een wat gee. Die werkwoord $\delta i \delta \omega \mu t$ staan in die participium praesens, dit wil se, dit is God wat altyd maar besig is om te gee; dit behoort tot sy wese (Van Leeuwen, 1926:359). Die vraag is of ons hier by die gawe van die Gees alleen moet dink aan Pinkster toe die Heilige Gees as God se eskatologiese gawe aan die kerk gegee is (Best, 1977:170 - "the present is non-temporal and describes the character of God rather than suggesting a continuous giving"), of wil Paulus hier wys op "de verlening van de Geest als een voortgaande werkzaamheid" (Bolkestein, 1974:104)? Beide opvattings hoef mekar nie uit te sluit nie. Dit is belangrik dat hier verduidelik word dat God wat oproep tot 'n heilige lewenswandel ook sy Heilige Gees gee om heilig te lewe. 
In die verhouding indikatief-paraklese speel die Heilige Gees dus 'n belangrike, ja onmisbare rol. Dit is die Heilige Gees as God se gawe wat aan die gelowiges die krag verleen om heilig te lewe, om God se voorskrifte met betrekking tot die sedelike lewe te gehoorsaam.

\section{HEILIGING DEUR DIE GEES}

Die heiligmaking is primêr ' $n$ gawe van God, maar tegelyk is dit 'n opgawe vir die kerk en vir elke gelowige. Die heiliging as goddelike gawe word deur Paulus uitdruklik in verband gebring met die Heilige Gees. In 2 Tessalonisense 2:13 skrywe Paulus oor heiligmaking deur die Gees.

Op die pad van heiligmaking is die gelowige van die Heilige Gees afhanklik. Dit beteken nie dat die heiligmaking net die werk van die Heilige Gees is nie. Die gelowige word opgeroep om die voorskrifte van God met betrekking tot 'n heilige lewe te gehoorsaam. Heiligmaking is God se werk. God moet dit doen. Maar die gelowige kan die voorskrifte tot heiliging alleen uitvoer deur die krag van die Heilige Gees. Daarom kom Paulus in 1 Tessalonisense 4:8, na die indringende vermaning tot heiliging van die lewe, met sy verwysing na die Heilige Gees. Deur die inwonende Gees, wie se hulp gelowig ingeroep en op wie se krag vertrou word, ontvang die gelowige die krag om God se voorskrifte te gehoorsaam (Versteeg, 1976:24).

Paulus verkondig in 1 Tessalonisense die indikatief van die wederkoms van Christus en in verband daarmee die paraklese van 'n heilige lewenswandel. Tegelykertyd wys hy in sy brief egter ook op God wat die Heilige Gees gee om wat hy eis, ook gelowig te kan doen. Geloof in God wat gee, skenk krag om dieselfde God wat eis te gehoorsaam.

Die paraklese, die imperatief, die gebod tot heiliging soos dit verkondig word, moet die mens tot gebed bring. Hierdie gebed is 'n gebed om die Heilige Gees (Floor, 1974:30). Augustinus het dit so treffend verwoord met sy beroemde gebed: "Here, gee wat u beveel en eis dan wat u wil".

\section{BIBLIOGRAFIE}

BEAUVERY, R. 1955. Pleonektein in 1 Thess.4,6a. Vertum Domini, 33:78-95.

BEST, E. 1977. The First and Second Epistles to the Thessalonians. London : A. \& Ch. Black.

BJERKELUND, C.J. 1967. Parakaleo. Oslo : Töpelmann. 
BOLKESTEIN, M.H. 1974. De brieven aan de Thessalonicenzen. Nijkerk : Callenbach.

CALVYN, J. 1895. Corpus reformatorum LXXX. Brunsvigae : Reuss.

COETZEE, J.C. 1980. Die blye boodskap. 1. Dic briewe van Paulus. Potchefstroom : Pro Rege.

DE KLERK, B.J. 1983. Dic gesag van die prediking van die Nuwe-Testamentiese briewe. Potchefstroom : PU vir CHO.

DELLING, G. 1959. Pleonektes. Theologisches Wörterbuch zum Neuen Testament VI:266-274. Stuttgart: Kohlhammer.

DIBELIUS, M. 1937. Aan die Thessaloniker I,II. Tübingen : Mohr.

FLOOR, L. 1974. Dic indikatief en die imperatief in die prediking. Theologica Reformata, XVII (10):1933.

FLOOR, S.J. 1983. Dic betekenis van hagiasmos in Hebrec̆rs 12:14: 'n filologiese studic. Potchefstroom : PU vir CHO.

FRAME, J.E. 1912. The Epistles of St. Paul to the Thessalonians. Edinburgh : Clark.

JEWETT, R. 1986. The Thessalonian Correspondence. Pauline Rhetoric and Millenarian Piety. Philadelphia : Fortress Press.

LLOYD-JONES, D.M. 1980. Christian unity. Edinburgh : Banner of Truth.

LOUW, J.P. \& NIDA, E.A. 1988. Greek-English Lexicon of the New Testament based on semantic domains. Vol. I. New York : United Bible Socicties.

MALHERBE, A.J. 1987. Paul and the Thessalonians: the philosophical tradition of pastoral care. Philadelphia : Fortress Press.

MASSON, Ch. 1957. Les deux Epitres de saint Paul aux Thessaloniciens. Paris : Neuchatel.

MORRIS, L. 1959. The first and second Epistles to the Thessalonians. Grand Rapids : Eerdmans.

RIGAUX, O.F.M. 1956. Saint Paul - Les Epitres aux Thessaloniciens. Paris : Gembloux.

RIDDERBOS, H.N. 1959. Aan de Romeinen. Kampen : Kok.

ROSSANO, P. 1954. De conceptu Pleonexia in Novo Testamento. (Verbum Domini, 32:257-265.)

SCHLATTER, A. 1921. Erlaüterungen zum Neuen Testament, II. Die Briefe des Paulus. Stuttgart : Kohlhammer.

SCHMITZ, O. 1954. Parakaleo. Theologisches Wörterbuch zum Neuen Testament V. Stultgart : Kohlhammer.

SCHRAGE, W. 1961. Dic konkreten Einzelgebole in der Paulinischen Paraenese. Stuttgart : Kohl.

STAAB, K. 1950. Paulusbriefc, II Thessalonikerbriefe. Regensburg : Topelmann.

VAN LEEUWEN, J. 1926. Paulus' zendbrieven aan Efeze, Colosse, Filemon en Thessalonika. Amsterdam : Bottenburg.

VELEMA, W.H. 1985. Geroepen tot heilig leven. Kampen : Kok.

VERSTEEG, J.P. 1976. De Geest en de gelovige. Kampen : Kok.

VERSTEEG, J.P. 1987. De brieven aan de Thessalonicenzen (In Mulder, H. red. Bijbels Handbock 3. Het Nieuwe Testament. Kampen : Kok p.365-381.)

WHOLENBERG, G. 1909. Der erste und zweitc Thessalonikerbrief. Leipzig. 
